\title{
Investigation of the effects of a high fish diet on inflammatory cytokines, blood pressure, and lipids in healthy older Australians
}

\author{
Jessica A. Grieger'**, Michelle D. Miller' and Lynne Cobiac ${ }^{1,2}$ \\ 'Department of Nutrition and Dietetics, Flinders Clinical and Molecular Medicine, Flinders Medical Centre, Bedford \\ Park, Australia; ${ }^{2}$ CSIRO Preventative Health Flagship, Adelaide, Australia
}

\section{Abstract}

Background: Aging is a condition of chronic inflammation. In healthy Australians $\geq 64$ years, the primary aim was to determine whether four servings/week of mixed fish (FISH) improves serum cytokines (i.e. C-reactive protein (CRP), IL-1, IL-6, TNF- $\alpha$ ) compared to a diet low in fish ( $<1$ serving/week, CONTROL); the secondary aims were to assess the effect of the diet on blood pressure and serum lipids (TC, HDL-C, TG, calculated LDL-C).

Methods: An 8-week randomized, parallel study, stratified by CRP ( $<3 \mathrm{mg} / \mathrm{L}$ vs. $\geq 3 \mathrm{mg} / \mathrm{L})$ on entry to the study. Compliance was measured using 3-day weighed food records in weeks 1 and 7 of the study. A 12-h fasting blood sample was taken at baseline and 8-weeks for erythrocyte fatty acids as confirmation of compliance, and measurement of serum cytokines and lipids. Blood pressure was measured at both time points. Results: Eighty participants completed the study (mean (SD) age: 69.6 (5.8) years). During week 1 of the study, mean \pm SEM daily dietary intake of very long chain omega-3 polyunsaturated fatty acids (VLCN n-3 PUFA) in FISH vs. CONTROL was $1,676 \pm 129 \mathrm{mg}$ vs. $27 \pm 5 \mathrm{mg}(p<0.001)$. Mean (SD) gram intake of study fish and meat was 121 (45) g and 123 (78) g, for those allocated to FISH and CONTROL, respectively. Mean \pm SEM percentage VLCN n-3 PUFA in erythrocytes at 8-weeks was higher in those allocated to FISH vs. CONTROL $(10.2 \pm 0.2 \%$ vs. $8.2 \pm 0.3 \%, p<0.001)$. There was no between-group difference in CRP $(n=80)$, IL-1 $\beta(n=33)$ or IL-6 $(n=21)$ concentrations, blood pressure, or lipids, at 8-weeks.

Conclusions: Eight weeks consumption of four servings/week fish did not affect serum cytokine concentrations, blood pressure or lipids compared to a diet low in fish. In healthy older adults with low inflammatory burden, our results do not support that short-term consumption of mixed fish has a beneficial effect on selected cardiovascular biomarkers.

Keywords: older adults; fish; C-reactive protein; omega-3 long chain fatty acids; blood pressure; lipids

To access the supplementary material to this article please see Supplementary files under Article Tools online

Received: 3 January 20I3; Revised: 8 September 20I3; Accepted: 9 December 20I3; Published: I5 January 20I4

$\mathrm{W}$ ith aging, the inflammatory process is aggravated. This may be a result of conditions such as cachexia (1), neurodegenerative diseases $(2,3)$, or depression (4). It is recognized that chronic, low-grade inflammation is associated with increased risk for cardiovascular, and a number of other, chronic diseases $(5,6)$. With aging, blood pressure also generally increases (7) and elevated blood pressure $(>140 / 90)$ is a risk factor for cardiovascular disease (CVD), specifically stroke (8). The ability of very long chain omega-3 polyunsaturated fatty acids (VLCN n-3 PUFA) that are contained in fish to impact markers of CVD continues to be investigated; however, clinical trials assessing increased intake of fish in older adults, who are at greater risk of CVD, are inconclusive.

In Australia, consumption of fish is low (9-11). In 1995, the estimated mean intake of total VLCN n-3 PUFA in those $>65$ years was $219 \mathrm{mg} /$ day, to which fish and seafood products contributed $48 \%$ (11). In a more recent survey of older adults in Australia $(n=854)$, the 
mean frequency of finfish/seafood consumption was 1.7 times/week (median intake $173 \mathrm{~g}$ ), however only $28 \%$ ( $n=242$ ) consumed $\geq 500 \mathrm{mg} /$ day VLCN $\mathrm{n}-3$ PUFA from finfish/seafood alone (12). These intakes are lower than current Australian recommendations for fish and VLCN n-3 PUFA consumption (10).

Findings from some observational studies reveal that dietary intakes of VLCN n-3 PUFA of $\geq 100 \mathrm{mg}$ /day in Western countries (13-15) or $\geq 470 \mathrm{mg} /$ day in the higher fish eating country of Japan (16), were associated with lower concentrations of inflammatory cytokines including C-reactive protein (CRP), IL-6, and intercellular- and vascular adhesion molecules. It is unclear whether consumption of fish in its whole form affects inflammatory cytokines in healthy older adults. Some observational studies demonstrated that fish consumption of 100-150 g/ week was associated with lower cytokine concentrations (15), particularly CRP $(17,18)$, and studies investigating dietary patterns have found that those which included fish were also associated with lower CRP concentrations (19, 20). Some intervention studies have assessed the impact of increased fish consumption on cytokine concentrations and cardiovascular risk markers in younger (21-24) and older populations (25-31). However, specifically in the studies among older adults, the fish intervention was either in combination with other omega-3 oils or foods $(28,31)$, included patients with non-active/previous cancer (32) or coronary heart disease (CHD) (30), was based on guidelines to lower cholesterol (27), was only conducted in men $(25,26)$ or the included fish was modified by different feeds $(25,30)$. The current study is therefore the first to assess a high fish diet in both healthy older men and women, without risk factors for CVD, and in conjunction with their usual diet on cytokine concentrations. Only two of the previous studies compared the fish intervention to a diet in which either $150 \mathrm{~g} /$ day chicken was used as a reference meal (25) or a mix of $150 \mathrm{~g} /$ day lean pork and chicken for 5 day/week (26). In Australia, recent surveys have suggested a decline in red meat consumption, even in the older age groups, whereas consumption of poultry has been relatively constant (33). Therefore, we chose to support the consumption of red meat, appropriate for this age group, by providing four servings/week of red meat to the CONTROL group.

Only two studies in older adults have assessed fish intake on blood pressure in which a positive association was found between a higher intake of fish (34) and higher serum levels of VLCN n-3 PUFA (35) with lower blood pressure. In combination with 8 -weeks of energy restriction, consumption of salmon three times/week lowered diastolic blood pressure in young, overweight, 20-40 year olds (36); and consumption of lean fish $\geq 4$ times/week reduced blood pressure in patients with CHD (37). No RCTs were found that specifically investigated the effects of increased fish intake on blood pressure in older adults.
Consumption of a range of mixed fish within the context of a usual dietary pattern in older adults, who are prone to some low-grade inflammation and who usually consume a relatively low intake of fish would therefore provide value in understanding whether increased fish intake affects cardiovascular risk markers.

The primary aims of the current study were to determine, in a group of healthy Australian adults $\geq 64$ years of age: whether consumption of four servings/week of mixed types of fish (FISH), improves serum cytokines (i.e. CRP, IL-1, IL-6, TNF- $\alpha$ ) compared to a typical Australian diet that is lower in fish ( $<1$ serving/week) and higher in red meat, CONTROL. The secondary aims were to identify whether consumption of a higher fish diet improves blood pressure and serum lipids (TC, HDLC, TG, and calculated LDL-C) compared to a typical Australian diet that is lower in fish and higher in red meat.

\section{Materials and methods}

\section{Experimental design}

This study was an 8-week randomized controlled, parallel study. Participants were randomized to either FISH, in which participants were provided eight servings of mixed fish per fortnight, equivalent to $\sim 800 \mathrm{mg} /$ day $\mathrm{EPA}+\mathrm{DHA}$, or CONTROL, in which participants consumed their usual diet as well as eight servings of red meat per fortnight (equivalent to $17 \mathrm{mg} /$ day EPA and $4 \mathrm{mg} /$ day DHA, Table 1). The amount of meat provided was $\sim 0.5$ serving/day (68 g/day) and was based on the recommended 1-1.5 daily servings of 'meat, fish, poultry, eggs, nuts and legumes' from the Australian Guide to Healthy Eating for men and women $>60$ years (38). Participants in both groups were advised to follow their otherwise usual dietary and physical activity patterns throughout the 8-week study. Between study groups, the food provided was designed to be no greater than $10 \%$ different for energy $(\mathrm{kJ})$, protein $(\mathrm{g})$, saturated fat $(\mathrm{g})$ and sodium $(\mathrm{g})$, except for total fat, which was nearly double in the FISH diet vs. CONTROL diet (7.0 g/day vs. 4.7 g/day). Participants collected their study foods from Flinders Medical Centre every two weeks, and for those who travelled long distances, at the 4-week time point. At this time, the study researcher interviewed each participant to determine compliance with the study protocol and ease of including study foods into their regular diet. For participants who were finding it difficult to consume the study foods, the study researcher provided verbal motivation for consuming these.

\section{Subjects}

A total of 126 community dwelling men and women $\geq 64$ years of age expressed interest in the study following newspaper advertisements, flyers and verbal invitations. 
Table 1. Composition of the provided study foods

\begin{tabular}{|c|c|c|c|c|c|c|c|c|c|}
\hline & $\begin{array}{l}\text { Energy } \\
(\mathrm{kJ})\end{array}$ & $\begin{array}{l}\text { Protein } \\
\text { (g) }\end{array}$ & $\begin{array}{l}\text { Total fat } \\
\text { (g) }\end{array}$ & $\begin{array}{l}\text { Saturated fat } \\
\text { (g) }\end{array}$ & $\begin{array}{l}\text { Sodium } \\
\text { (mg) }\end{array}$ & $\begin{array}{l}\text { EPA } \\
(\mathrm{mg})\end{array}$ & $\begin{array}{l}\text { DHA } \\
(\mathrm{mg})\end{array}$ & $\begin{array}{c}\mathrm{EPA}+\mathrm{DHA} \\
(\mathrm{mg})\end{array}$ & $\begin{array}{l}\text { DPA } \\
(\mathrm{mg})\end{array}$ \\
\hline \multicolumn{10}{|l|}{ FISH: Weeks I and 2} \\
\hline Atlantic salmon-skin off, $145 \mathrm{~g}^{\mathrm{a}}$ & 1,056 & 32.0 & 13.6 & 3.2 & 59 & 945 & 1,035 & 1,980 & - \\
\hline Atlantic salmon-skin off, $145 \mathrm{~g}^{\mathrm{a}}$ & 1,056 & 32.0 & 13.6 & 3.2 & 59 & 945 & 1,035 & 1,980 & - \\
\hline Ocean trout-skin on, $150 \mathrm{~g}^{\mathrm{a}}$ & 1,630 & 28.2 & 30.3 & 7.8 & 41 & 1,210 & 2,200 & 3,430 & - \\
\hline Ocean trout-skin on, $150 \mathrm{~g}^{\mathrm{a}}$ & 1,630 & 28.2 & 30.3 & 7.8 & 41 & 1,210 & 2,200 & 3,430 & - \\
\hline Flavored canned salmon, $95 \mathrm{~g}^{\mathrm{a}}$ & 559 & 13.3 & 6.8 & 1.0 & 271 & 114 & 233 & 347 & - \\
\hline Flavored canned tuna, $95 \mathrm{~g}^{\mathrm{a}}$ & 537 & 17.3 & 6.3 & 0.8 & 326 & 17 & 148 & 164 & - \\
\hline $\begin{array}{l}\text { Canned sardines in spring water, } \\
110 \mathrm{~g}^{\mathrm{a}}\end{array}$ & 710 & 13.7 & 12.5 & 3.4 & 180 & 750 & $\mathrm{I}, \mathrm{I} 20$ & $\mathrm{I}, 880$ & - \\
\hline Canned pink salmon, $105 \mathrm{~g} \mathrm{pack}^{\mathrm{a}}$ & 484 & 18.6 & 4.9 & 1.2 & 280 & 502 & 683 & $\mathrm{I}, \mathrm{I} 85$ & - \\
\hline \multicolumn{10}{|l|}{ FISH: Week 3 and 4} \\
\hline $\begin{array}{l}\text { Marinated Atlantic salmon-skin off, } \\
\qquad 145 \mathrm{~g}^{\mathrm{a}}\end{array}$ & $\mathrm{I}, 380$ & 27.1 & 23.5 & 5.4 & 312 & 1,300 & 1,530 & 2,830 & - \\
\hline $\begin{array}{l}\text { Marinated Atlantic salmon-skin off, } \\
\qquad 145 \mathrm{~g}^{\mathrm{a}}\end{array}$ & $\mathrm{I}, 380$ & 27.1 & 23.5 & 5.4 & 312 & $\mathrm{I}, 300$ & 1,530 & 2,830 & - \\
\hline Canned red salmon, $105 \mathrm{~g}^{\mathrm{a}}$ & 557 & 18.4 & 6.9 & 1.5 & 324 & 494 & 762 & 1,256 & - \\
\hline Flavored canned salmon, $95 \mathrm{~g}^{\mathrm{a}}$ & 559 & 13.3 & 6.8 & 1.0 & 271 & 114 & 233 & 347 & - \\
\hline Tuna slices in spring water, $105 \mathrm{~g}^{\mathrm{a}}$ & 397 & 21.7 & 0.7 & 0.2 & 185 & 29 & 215 & 244 & - \\
\hline $\begin{array}{l}\text { Lightly seasoned frozen fish fillets, } \\
\qquad 200 \mathrm{~g}^{\mathrm{a}}\end{array}$ & $\mathrm{I}, 340$ & 29.2 & 14.8 & 2.0 & 260 & 200 & 500 & 700 & - \\
\hline Canned tuna in spring water, $95 \mathrm{~g}^{\mathrm{a}}$ & 227 & 12.1 & 0.5 & 0.3 & 139 & 0.2 & 20.0 & 147 & - \\
\hline \multicolumn{10}{|l|}{ MEAT: Weeks I and 2} \\
\hline Beef scotch fillet, lean, raw, $125 \mathrm{~g}^{\mathrm{b}}$ & 758.75 & 29 & 9.375 & 2.875 & 68.75 & 30 & 5 & 35 & 33.75 \\
\hline Beef scotch fillet, lean, raw, $125 \mathrm{~g}^{\mathrm{b}}$ & 758.75 & 29 & 9.375 & 2.875 & 68.75 & 30 & 5 & 35 & 33.75 \\
\hline Frozen veal schnitzel, $140 \mathrm{~g}^{\mathrm{c}}$ & 1,289 & 18.06 & 14.56 & 4.48 & 882 & & & & \\
\hline Lamb rump, lean, raw, $125 \mathrm{~g}^{\mathrm{b}}$ & 677.5 & 28.125 & 5.375 & 1.75 & 81.25 & 23.8 & 13 & 36.8 & 46.3 \\
\hline Beef scotch fillet, lean, raw, $125 \mathrm{~g}^{\mathrm{b}}$ & 758.75 & 29 & 9.375 & 2.875 & 68.75 & 30 & 5 & 35 & 33.75 \\
\hline Ham deli meat, $50 \mathrm{~g}^{\mathrm{c}}$ & 184 & 7.9 & 1.5 & 0.3 & 293 & & & & \\
\hline Ham deli meat, $50 \mathrm{~g}^{\mathrm{c}}$ & 184 & 7.9 & 1.5 & 0.3 & 293 & & & & \\
\hline \multicolumn{10}{|l|}{ MEAT: Week 3 and 4} \\
\hline Beef mince, $10 \%$ fat, $150 \mathrm{~g}^{\mathrm{b}}$ & 1,112 & 30.15 & 16.2 & 5.85 & 96 & $|4|$ & 31.5 & 172.5 & 217.5 \\
\hline Beef mince, $10 \%$ fat, $150 \mathrm{~g}^{\mathrm{b}}$ & 1,112 & 30.15 & 16.2 & 5.85 & 96 & $|4|$ & 31.5 & 172.5 & 217.5 \\
\hline Lamb rump, lean, raw, $125 \mathrm{~g}^{\mathrm{b}}$ & 677.5 & 28.125 & 5.375 & 1.75 & 81.25 & 23.8 & 13 & 36.8 & 46.3 \\
\hline Beef scotch fillet, lean, raw, $125 \mathrm{~g}^{\mathrm{b}}$ & 758.75 & 29 & 9.375 & 2.875 & 68.75 & 30 & 5 & 35 & 33.75 \\
\hline Pork loin chop, $140 \mathrm{~g}^{\mathrm{b}}$ & 440 & 22.2 & 1.7 & 0.6 & 66 & 0 & 6 & 6 & 9 \\
\hline $\begin{array}{l}\text { Frozen beef satay convenience } \\
\text { meal, } 375 \mathrm{~g}^{\mathrm{c}}\end{array}$ & 2,378 & 25.9 & 20.6 & 8.6 & 675 & & & & \\
\hline Beef scotch fillet, lean, raw, $125 \mathrm{~g}^{\mathrm{b}}$ & 758.75 & 29 & 9.375 & 2.875 & 68.75 & 30 & 5 & 35 & 33.75 \\
\hline Pork loin chop, $140 \mathrm{~g}^{\mathrm{b}}$ & 440 & 22.2 & 1.7 & 0.6 & 66 & 0 & 6 & 6 & 9 \\
\hline
\end{tabular}

${ }^{a}$ Analyses were conducted by AsureQuality Limited (Auckland New Zealand). All samples submitted for analyses were composite samples from a minimum of three production dates. Samples were homogenized with stainless steel cutters, packed in plastic bags protected from light and frozen before being shipped to the laboratory. All samples were analyzed in duplicates. Reagent blank (same procedure but omitting the sample), spikes and standard reference materials were prepared as per the laboratory's standard operating procedure. The laboratory contracted to undertake the analyses was accredited and complied to the requirements for the competence of testing and calibration laboratories ISO/IEC I7025:2005.

${ }^{b}$ Nutrient profiles were obtained from AUSNUT 2007 or ${ }^{c}$ nutrient information panel of actual products.

Ninety-two were eligible for screening; however eight did not attend. Inclusion criteria were: BMI $\geq 18.5 \mathrm{~kg} / \mathrm{m}^{2}$, usual consumption of $\leq 1$ serving of fish/seafood per week, willing to consume eight servings of fish or red meat per fortnight, able to provide written informed consent and attend assessment visits at Flinders Medical 
Centre. Exclusion criteria were: allergies to fish/seafood, vegetarian, intake of lipid-lowering medications; intake of lipid-lowering supplements (e.g. psyllium, fish oil capsules, soy lecithin, phytoestrogens or to cease 3 weeks prior to study commencement), use of anti-inflammatory medications on a regular basis or if experiencing an acute episode within 1 week of the screening visit, presence of diabetes, liver, kidney, thyroid diseases (unless controlled and stable on replacement medication), presence of other endocrine disorders from self-reported medical history, weight loss or gain of $>10 \%$ body weight in the prior 6 months, or clinically diagnosed depression or dementia. Of the 84 respondents who attended the clinic visit, all were eligible for the RCT, however one participant withdrew before randomization, leaving 83 to be randomized. The Southern Adelaide Clinical Research Ethics Committee granted ethical approval. The clinical trial was registered with the Australian New Zealand Clinical Trials Registry, trial number 336393. Written informed consent was obtained from all subjects.

\section{Clinic measurements}

All assessments were taken at baseline and at 8-weeks. Body weight and height were measured to $0.1 \mathrm{~kg}$ and $0.1 \mathrm{~cm}$, respectively, while wearing light clothing and without shoes, on a digital height and weight wireless measuring station (SECA, model 284, Germany). Blood pressure was measured using a hospital grade non-invasive automated sphygmomanometer (Criticare Systems Inc., USA). After $5 \mathrm{~min}$ of rest, blood pressure was taken three times and the average reading was used.

\section{Laboratory measurements}

At baseline and at 8-weeks, participants arrived at the clinic following a 12-h overnight fast in which only water was allowed to be consumed. Nursing staff confirmed the fast before taking $10 \mathrm{ml}$ of blood by asking them their last mealtime from the prior evening. After $30 \mathrm{~min}$ of clotting, whole blood was centrifuged at 3,500 RPM, $24^{\circ} \mathrm{C}$ for $10 \mathrm{~min}$ (Beckman GS-6R). Serum was separated, aliquoted, and stored at $-80^{\circ} \mathrm{C}$ until all participants completed the study. Aliquots were then thawed, and total cholesterol, HDL-C, triacylglycerol, and high-sensitive CRP (hs-CRP) (limit of detection $\leq 0.3 \mathrm{mg} / \mathrm{L}$ ) were analyzed enzymatically (Siemens Advia 2,400 Chemistry System). LDL cholesterol was calculated using the Friedewald Equation (39). Inflammatory cytokines (IL6 , IL-1 $\beta$ and TNF- $\alpha$ ) were measured using commercial cytokine enzyme-linked immunosorbent assays (ELISA) (BD Systems, San Diego, CA). The limits of detection for IL-6, IL-1 $\beta$ and TNF- $\alpha$ were all $<5 \mathrm{pg} / \mathrm{ml}$. The inter-assay and intra-assay CV for IL- 6 were $6-8$ and $2-3 \%$, for IL- $1 \beta$ were $7-10$ and $2-4 \%$ and for TNF- $\alpha$ were $3-5$ and $1-3 \%$, respectively.

\section{Compliance}

Three-day weighed food records

Dietary intakes were measured using 3-day weighed food records (any 2 week days and any 1 weekend day) and were completed during week 1 and week 7 of the study to assess study compliance. All participants were instructed on how to fill out their food records at the baseline visit and were provided a set of digital food scales (Kenwood DS607 Digital Food Scales, Australia).

Fatty acids

Compliance was assessed using measurement of fatty acids in erythrocytes and plasma phospholipids (DHA, DPA, EPA, total n-3 fatty acids, total n-6 fatty acids, and total saturated fatty acids) collected into heparinized tubes.

Lipid extraction from plasma phospholipids. Plasma was separated from erythrocytes by centrifugation $(5 \mathrm{~min}$ at $1,000 \mathrm{~g}$ ) and $1 \mathrm{ml}$ plasma was added to $0.5 \mathrm{ml}$ saline, $2 \mathrm{ml}$ of methanol and $4 \mathrm{ml}$ of chloroform. The samples were centrifuged and the lower chloroform phase (containing lipids) was transferred to a $20 \mathrm{ml}$ scintillation vial and evaporated to dryness by a vacuum concentrator. $150 \mathrm{ml}$ of chloroform: methanol (9:1) was added to the vial in preparation for thin layer chromatography (TLC).

Lipid extraction from erythrocytes. Erythrocytes were rinsed free of plasma three times in isotonic saline and $1 \mathrm{ml}$ packed cells were mixed with $0.5 \mathrm{ml}$ saline, $2 \mathrm{ml}$ of isopropanol, and $4 \mathrm{ml}$ of chloroform. The samples were centrifuged and the lower chloroform phase was transferred to a vial and evaporated to dryness. About $150 \mathrm{ml}$ of chloroform: methanol $(9: 1)$ was added to the vial in preparation for TLC.

Thin Layer Chromatography. The phospholipids from all tissues were isolated using TLC (Silica gel $60 \mathrm{H}$, Merck, Darmstadt Germany) using a ratio of 3:1 (v/v) of petroleum spirits: acetone. Phospholipid bands were visualized under an ultraviolet lamp and scraped into vials containing $1 \% \mathrm{H}_{2} \mathrm{SO}_{4}$ in methanol for trans-esterification for $3 \mathrm{~h}$ at $70^{\circ} \mathrm{C}$. After cooling, water and $n$-heptane were added to the mixture and the upper layer containing the resulting fatty acid methyl esters (FAME) was transferred into $2 \mathrm{ml}$ gas liquid chromatography (GLC) vials containing anhydrous $\mathrm{Na}_{2} \mathrm{SO}_{4}$.

Gas chromatographic analysis of FAME. FAMEs were separated and quantified using a Hewlett-Packard 6,890 gas chromatograph equipped with a $50 \mathrm{~m}$ capillary column (0.33 mm ID) coated with BPX-70 (0.25 m film thickness SGE Pty Ltd Victoria Australia). The injector temperature was set at $250^{\circ} \mathrm{C}$ and the detector (flame ionization) temperature at $300^{\circ} \mathrm{C}$. The initial oven temperature was 
Table 2. Baseline and 8-week measurements amongst the study population

\begin{tabular}{|c|c|c|c|c|c|c|c|c|}
\hline & \multicolumn{4}{|c|}{ Baseline } & \multicolumn{4}{|c|}{ Week 8} \\
\hline & \multicolumn{2}{|c|}{ Control $^{\mathrm{a}}$} & \multicolumn{2}{|r|}{ Fish $^{\mathrm{a}}$} & \multicolumn{2}{|c|}{ Control $^{\mathrm{a}}$} & \multicolumn{2}{|c|}{ Fish $^{\mathrm{a}}$} \\
\hline & $n$ & & $n$ & & $n$ & & $n$ & \\
\hline Weight (kg) & 37 & $73.8 \pm 2.1$ & 43 & $75.7 \pm 2.2$ & 37 & $73.6 \pm 2.0$ & 43 & $75.8 \pm 2.1$ \\
\hline BMI $\left(\mathrm{kg} / \mathrm{m}^{2}\right)$ & 37 & $26.4 \pm 0.6$ & 43 & $26.5 \pm 0.6$ & 37 & $26.3 \pm 0.6$ & 43 & $26.5 \pm 0.6$ \\
\hline Systolic blood pressure (mmHg) & 37 & $126 \pm 2$ & 43 & $126 \pm 2$ & 37 & $126 \pm 3$ & 43 & $124 \pm 3$ \\
\hline Diastolic blood pressure $(\mathrm{mmHg})$ & 37 & $67 \pm 1$ & 43 & $69 \pm 1$ & 37 & $66 \pm 1$ & 43 & $68 \pm 2$ \\
\hline $\mathrm{CRP}(\mathrm{mg} / \mathrm{L})^{\mathrm{b}}$ & 37 & $0.8(0.5,1.3)$ & 43 & $1.17(0.8,1.8)$ & 37 & $0.8(0.5,1.3)$ & 43 & $\mathrm{I} .0(0.7,1.5)$ \\
\hline $\mathrm{IL}-\mathrm{I} \beta(\mathrm{pg} / \mathrm{ml})^{\mathrm{b}, \mathrm{c}}$ & 15 & $6.9(4.7,10.1)$ & 18 & $8.11(5.3,12.4)$ & 15 & $7.7(6.2,9.4)$ & 18 & $7.3(6.0,8.8)$ \\
\hline IL-6 (pg/ml) $)^{\mathrm{b}, \mathrm{c}}$ & 10 & $7.9(5.4,11.4)$ & II & $7.21(5.4,9.7)$ & 10 & $7.5(5.9,9.6)$ & II & $7.7(5.2,11.4)$ \\
\hline Total cholesterol (mmol/L) & 37 & $5.5 \pm 0.2$ & 43 & $5.5 \pm 0.1$ & 37 & $5.4 \pm 0.2$ & 43 & $5.6 \pm 0.1$ \\
\hline $\mathrm{HDL}-\mathrm{C}(\mathrm{mmol} / \mathrm{L})$ & 37 & $1.6 \pm 0.1$ & 43 & $1.7 \pm 0.1$ & 37 & $1.7 \pm 0.1$ & 43 & $1.8 \pm 0.1$ \\
\hline LDL-C (mmol/L) & 37 & $3.3 \pm 0.1$ & 43 & $3.2 \pm 0.1$ & 37 & $3.2 \pm 0.1$ & 43 & $3.4 \pm 0.1$ \\
\hline Triacylglycerol (mmol/L) & 37 & $1.4 \pm 0.1$ & 43 & $I . I \pm 0.1$ & 37 & $1.3 \pm 0.1$ & 43 & $1.0 \pm 0.1$ \\
\hline
\end{tabular}

BMI: body mass index; CRP: C-reactive protein; IL-I $\beta$ : interlukin-I beta; IL-6: interleukin 6; HDL-C: high-density lipoprotein cholesterol; LDL-C: low-density lipoprotein cholesterol.

${ }^{a}$ Data reported as mean \pm standard error of the mean.

${ }^{b}$ Data reported as geometric means $(95 \% \mathrm{Cl})$.

${ }^{\circ}$ Values only reported if above limit of detection.

$140^{\circ} \mathrm{C}$ and was programmed to rise to $220^{\circ} \mathrm{C}$ at $5^{\circ} \mathrm{C}$ per minute. Helium was used as the carrier gas at a velocity of $35 \mathrm{~cm}$ per second. Individual fatty acids were identified by comparison with known fatty acid methyl ester standards (Nuchek Prep Inc., Elysian, USA) and expressed as a percentage of total fatty acids (weight percentage) (40).

\section{Sample size}

The sample size was based on previous studies that showed a $19 \%(0.4 \mathrm{mg} / \mathrm{L})$ reduction in CRP following $360 \mathrm{mg} /$ day $\mathrm{EPA}+\mathrm{DHA}$ as fish oil for 3 weeks in hyperlipidemic patients ( $n=15, \sim 55$ years) (41); a $13 \%$ $(0.19 \mathrm{mg} / \mathrm{L})$ reduction in CRP following $2 \times 150 \mathrm{~g} /$ week of salmon for 6 months $(1,400 \mathrm{mg} /$ day total omega-3; $n=54, \sim 54$ years $)(29)$; and an $8 \%(0.13 \mathrm{mg} / \mathrm{L})$ reduction in CRP following $2 \times 150 \mathrm{~g} /$ week cod $(257 \mathrm{mg} /$ day total omega-3 for 6 months; $n=51, \sim 57$ years) (29). The calculated sample sizes required from these respective studies were 20,8 and 17 . As the target study population was older, free of disease, and may have a slightly higher inflammatory status at baseline, we anticipated a larger sample size would be required to find a similar significant change in CRP from the FISH diet. Therefore, the current study aimed to recruit 90 subjects in order to have 40 subjects complete the 8-week study in each group, with sufficient power to detect a CRP change of $13 \%(0.24 \mathrm{mg} / \mathrm{L})$ for those allocated to the FISH diet. An independent statistician using ralloc.ado version 3.6.1 in Stata version 11.1 created the randomization schedule. The randomization was stratified by screening CRP concentrations ( $<3 \mathrm{mg} / \mathrm{L}$ vs. $\geq 3 \mathrm{mg} / \mathrm{L}$ ) in order to determine whether diet affected CRP differently between those with different baseline CRP concentrations. Block sizes of 2, 4 and 6 were used and were chosen at random; treatment allocations were randomly permuted and balanced within blocks.

\section{Statistical analyses}

Statistical analyses were performed using SPSS 19 for Windows (SPSS, Inc., Chicago, IL, USA). Frequencies and descriptives of the study population are reported as mean (SD), or between groups as mean (SEM). Prior to hypothesis testing, data were examined for normality. Distribution was normal except for CRP, IL-1 and IL-6, which were normalized using natural logarithmic transformation with the exponentiated (geometric) means (95\% confidence intervals) presented. Primary and secondary outcomes at 8-weeks were tested using ANCOVA (univariate analysis of variance, adjusting for baseline values). As a secondary analysis, the absolute change in CRP was assessed with CRP strata as a fixed factor (group $\times$ CRP stratification interaction), without adjustment for baseline CRP. Adjustment for multiple comparisons was made using the Sidak correction. The alpha level of significance was $p<0.05$.

\section{Results}

\section{Baseline characteristics}

A total of 83 participants started the study; however one participant withdrew from the FISH diet (too ill to 
continue, aged 81 years) and two withdrew from the CONTROL diet $(n=1$ did not turn up for final visit despite several phone calls and emails, aged 72 years; and $n=1$ chose to continue with Zocor medication 2 weeks into the study, aged 66 years), leaving 80 participants to complete the study. The mean (SD) age of completed participants was 69.6 (5.8) years (range 64-85 years) and $51 \%$ were female. Mean $(95 \%$ CI) baseline CRP concentrations of the completed participants in the low and high CRP strata are shown in Supplementary file. There were no baseline differences in CRP strata concentrations between those allocated to the FISH diet and those allocated to the CONTROL diet. Characteristics of the study participants are represented in Table 2.

\section{Study compliance}

Food intake

Table 3 describes the mean gram intake and some nutrient intakes consumed from the study fish and meat, as well as by non-study fish/meat during week 1 and week 7 of the study, in FISH and CONTROL. For those allocated to the FISH diet, no other fish was consumed at either time point. For those allocated to the CONTROL diet, one serving of fish was consumed by one participant in week 1 and week 7 of the study. Supplementary file shows the mean energy and nutrient intakes between groups during week 1 and week 7 of the study. Intakes of VLCN n-3 PUFA was higher for those allocated to the FISH diet at both time points compared to those allocated to the CONTROL diet, whereas the intakes of most other nutrients were generally not different between groups.

Fatty acids

Mean \pm SEM percentage VLCN $n-3$ PUFA in erythrocytes at 8-weeks was higher for those allocated the FISH diet vs. CONTROL diet $(10.2 \pm 0.2 \%$ vs. $8.2 \pm 0.3 \%$, $p<0.001$ ) (Table 4) and this was also true of plasma phospholipids (Supplementary file). Percentage total n-6 fatty acids in plasma phospholipids, but not erythrocytes, was lower in those allocated the FISH diet vs. CONTROL diet at 8-weeks

\section{Primary outcomes: inflammatory cytokines}

The mean values of CRP between groups are reported in Table 2. There was no difference in 8-week CRP concentrations between groups. In the secondary analysis assessing the change in CRP over time, there was a diet effect according to CRP strata $(p=0.017)$ : in CONTROL, those with high CRP had a larger increase in CRP over the study $(n=7, \Delta=+3.37(3.24) \mathrm{mg} / \mathrm{L})$ compared to those with low CRP $(n=30, \Delta=+0.14(0.23) \mathrm{mg} / \mathrm{L}$, $p=0.046$, Fig. 1). The change in CRP in the FISH group was not different between those with low $(n=32$, $\Delta=-0.13(0.18) \mathrm{mg} / \mathrm{L})$ or high CRP $(n=11, \Delta=-1.15$ (1.5) $\mathrm{mg} / \mathrm{L}, p=0.27)$.

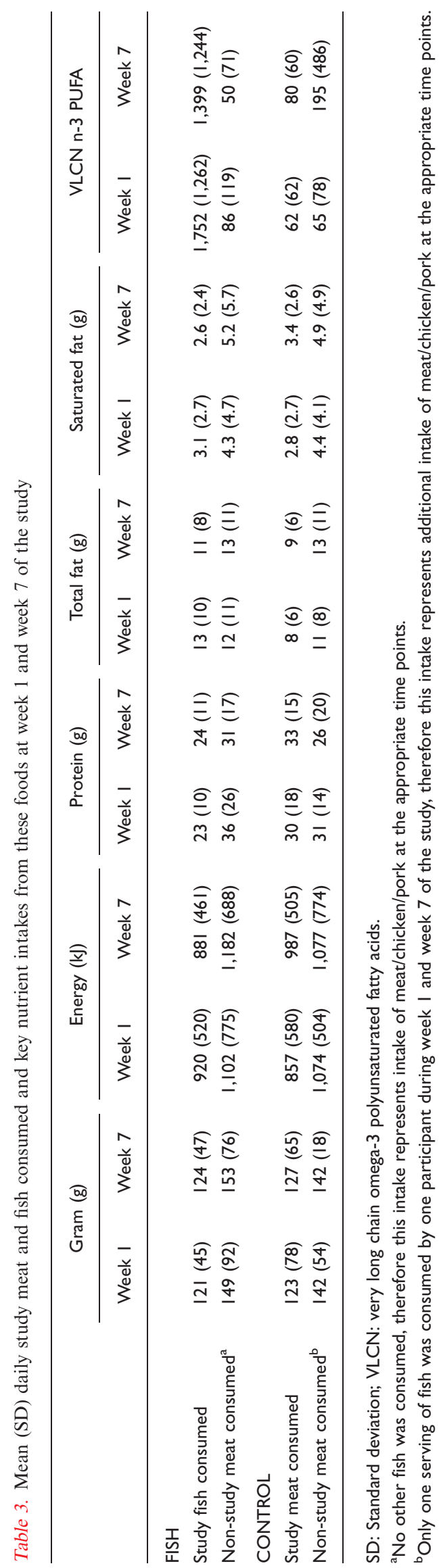


Table 4. Mean $( \pm$ SEM) percentage concentrations of fatty acids measured in erythrocytes at baseline and after 8-weeks consumption of a CONTROL $(n=37)$ or FISH $(n=43)$ diet

\begin{tabular}{llcc}
\hline & Group & Baseline (\%) & Week 8 (\%) \\
\hline Total saturated fatty & Control & $44.2 \pm 0.2$ & $44.1 \pm 0.3$ \\
acids & Fish & $44.1 \pm 0.2$ & $44.8 \pm 0.2$ \\
Total n-6 fatty acids & Control & $27.0 \pm 0.4$ & $26.6 \pm 0.4$ \\
& Fish & $27.2 \pm 0.4$ & $25.5 \pm 0.3^{\dagger}$ \\
Arachidonic acid & Control & $12.0 \pm 0.3$ & $12.4 \pm 0.2$ \\
& Fish & $12.5 \pm 0.2$ & $11.8 \pm 0.2^{*}$ \\
Total monounsaturated & Control & $18.4 \pm 0.2$ & $17.8 \pm 0.2$ \\
fatty acids & Fish & $18.2 \pm 0.2$ & $17.7 \pm 0.2$ \\
Total n-3 fatty acids & Control & $9.7 \pm 0.4$ & $8.4 \pm 0.3$ \\
& Fish & $9.3 \pm 0.3$ & $10.4 \pm 0.2^{\ddagger}$ \\
Alpha linoleic acid & Control & $0.147 \pm 0.008$ & $0.149 \pm 0.007$ \\
& Fish & $0.126 \pm 0.008$ & $0.136 \pm 0.008$ \\
Linoleic acid & Control & $10.3 \pm 0.2$ & $9.8 \pm 0.2$ \\
& Fish & $10.2 \pm 0.2$ & $9.8 \pm 0.2$ \\
VLCN n-3 PUFA & Control & $9.5 \pm 0.4$ & $8.2 \pm 0.3$ \\
& Fish & $9.2 \pm 0.3$ & $10.2 \pm 0.2^{\ddagger}$ \\
EPA & Control & $1.5 \pm 0.1$ & $1.1 \pm 0.3$ \\
& Fish & $1.3 \pm 0.1$ & $1.7 \pm 0.1^{\ddagger}$ \\
DPA & Control & $3.0 \pm 0.1$ & $2.8 \pm 0.1$ \\
& Fish & $2.8 \pm 0.1$ & $2.8 \pm 0.1$ \\
DHA & Control & $5.0 \pm 0.2$ & $4.4 \pm 0.2$ \\
& Fish & $5.0 \pm 0.2$ & $5.7 \pm 0.1^{\ddagger}$ \\
\hline
\end{tabular}

SEM: standard error of the mean; VLCN n-3 PUFA: very long chain omega-3 polyunsaturated fatty acids; EPA: eicosapentaenoic acid; DPA: docosapentaenoic acid; DHA: docosahexanoic acid.

${ }^{*} p<0.05,{ }^{\dagger} p<0.01,{ }^{\dagger} p<0.001$ between groups (analyzed using univariate analysis of variance, adjusting for baseline values).

All of the TNF- $\alpha$ serum samples were below the limits of detection $(<5 \mathrm{pg} / \mathrm{ml})$ and were therefore unable to be included in the analyses. Mean concentrations of IL-1 $\beta$ and IL-6 that were detectable in serum are reported in Table 2. Diet allocation had no effect on IL-1 $\beta$ or IL-6 at 8 -weeks.

\section{Secondary outcomes: lipids, blood pressure}

There was no effect of diet allocation on blood pressure or lipids (Table 2).

\section{Discussion}

This project was the first to be conducted among a group of healthy older adults in Australia, to assess whether 8 -weeks consumption of four servings/week mixed fish reduces inflammatory cytokines, compared to a typical Australian diet that is lower in fish and higher in red meat. The current study identified that compared to a low fish diet, consumption of four servings/week fish did not affect concentrations of cytokines overall, nor have any effect on the secondary outcomes, blood pressure and lipids. In a secondary analysis assessing the change in CRP over time, there was a diet effect according to CRP strata; those with CRP concentrations $\geq 3 \mathrm{mg} / \mathrm{L}$ in the control group had larger increases in CRP over the study compared to those with CRP concentrations $<3 \mathrm{mg} / \mathrm{L}$; fish had no effect on the change in CRP in participants with CRP $\geq 3$ or $<3 \mathrm{mg} / \mathrm{L}$.

Compliance with the intervention was appropriate as we found an increase in VLCN n-3 PUFA in erythrocytes in the fish group, and a decrease in the control group. Consumption of fish and meat, assessed by the 3-day weighed food records in weeks 1 and 7, was also satisfactory with high intakes of VLCN n-3 PUFA in the fish group. The amount of non-study meat that was consumed at both time points was similar between groups, and it was evident that the control group adhered to the study protocol as, except for one participant, no fish was consumed. We did not find any changes in percent n-6 fatty acids or DPA in erythrocytes (or plasma phospholipids) in the control group, therefore we can speculate that intake of red meat during the study period was comparable to usual intake.

In the current study, the increased consumption of fish did not decrease serum cytokines. The mechanisms relating long chain fatty acids and inflammation are emerging and are the result of the increased incorporation of VLCN n-3 PUFA into plasma phospholipids (42). Arachidonic acid (ARA, an omega 6 PUFA) is usually the major substrate for eicosanoid synthesis; eicosanoids are the most important mediators and regulators of inflammation (43). The incorporation of the VLCN n-3 PUFA (EPA and DHA) occurs at the expense of ARA. Thus, the normal pro-inflammatory response that would occur in response to ARA and its derivatives (e.g. prostaglandins, thromboxanes and leukotrienes) is reduced. The increased incorporation of VLCN n-3 PUFA and decreased ARA leads to a dampening of the proinflammatory state, and toward an anti-inflammatory state. Therefore, the fact that the increased intake of fish did not impact measures of inflammation indicates that either the dose of VLCN n-3 PUFA may have been too low, or that initial inflammatory status was not high enough to identify a notable effect. However, the sample size in which concentrations of IL-1 $\beta(n=33)$ and IL-6 $(n=21)$ was detected was small and therefore the low statistical power along with large variation in cytokine concentrations, would partly explain our result. Cell culture studies and some animal feeding studies have shown that cytokine inhibition by omega- 3 is mediated by inactivation of $\mathrm{NF \kappa B}$, a principle transcription factor (44). It would have been of interest to assess gene expression in this study and assess how fatty acids might affect activation of $\mathrm{NF \kappa B}$ in our healthy older adult sample. 


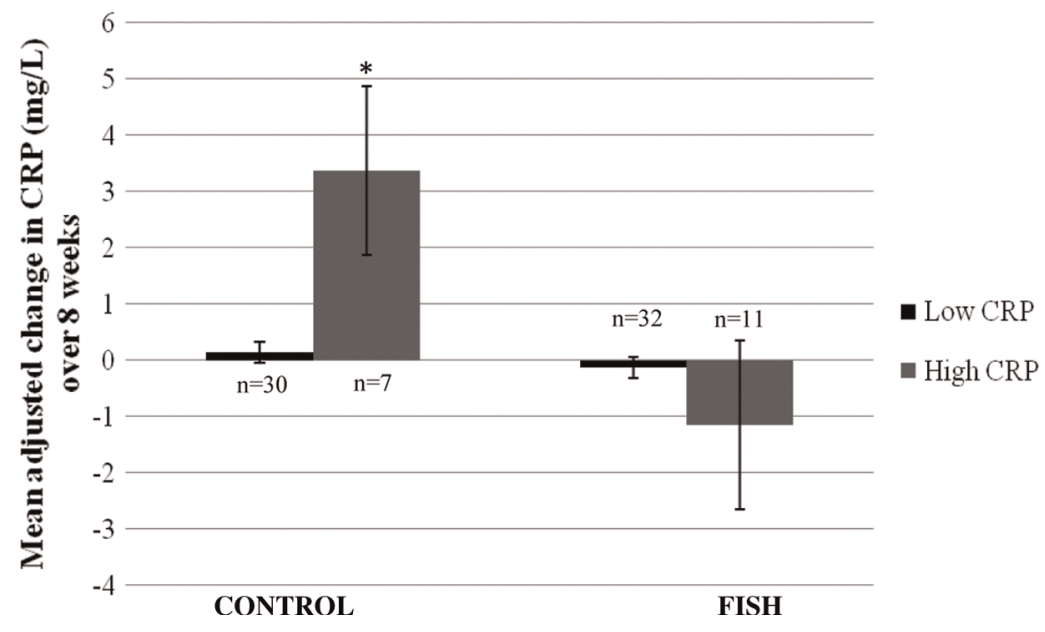

Fig. 1. Mean adjusted changes in CRP over 8-weeks between CONTROL and FISH.

Group $\times$ CRP strata interaction $(p=0.017)$ using the Sidak test for multiple comparisons.

${ }^{*} p=0.046$ between high and low CRP in CONTROL.

Several other RCTs in older adults have assessed fish consumption on inflammatory cytokines (25-31); however, these studies were conducted in those who were medically unwell or were in conjunction with other therapies. The increase in VLCN n-3 PUFA following the fish diet in our study was slightly lower compared to other intervention studies utilizing fish; however, the prescribed daily VLCN n-3 PUFA dose from fish in our study was also generally lower $(\sim 800 \mathrm{mg} /$ day vs. $>1.2 \mathrm{~g} /$ day $)$. Although our intention was to use healthy individuals, the specific use of older adults was novel and we anticipated a higher inflammatory status as a result of the aging process (irrespective of this group having no risk factors for CVD). Mean CRP values at baseline were comparable to those previous studies that assessed fish and inflammation, but the effect of increasing VLCN n-3 PUFA appears most effective with higher levels of inflammation. This conclusion was also indicated in a previous review, such that patients with an inflammatory condition might be more sensitive to the immunomodulatory effects of VLCN n-3 PUFA compared to healthy subjects (45).

We used CRP as the primary outcome measure as it has been consistently found to be an independent predictor of CVD (46). The use of an hs-CRP assay also enables low levels of CRP to be detected in peripheral blood, indicating low-grade inflammation (47). We acknowledge that because CRP is an acute-phase reactant some intraindividual variability may occur in testing, and low-grade inflammation can produce minor elevations of CRP. Although we attempted to have all participants' blood taken while they were free of any symptomatic illness, the low level of CRP at baseline suggests that amongst healthy older adults, the benefits of increased consumption does not provide an anti-inflammatory benefit. It would be of interest to assess the effects of increased fish consumption in a larger group of healthy adults with CRP $>3 \mathrm{mg} / \mathrm{L}$, and to determine whether a clinically relevant reduction in CRP occurs.

The effect of VLCN n-3 PUFA on blood pressure has been described; however, the positive effect of high dose VLCN n-3 PUFA supplementation on blood pressure is small (48). For example, in a meta-regression of 36 RCTs, VLCN n-3 PUFA supplementation decreased systolic and diastolic blood pressure in those $>45$ years by -2.72 and $-2.32 \mathrm{mmHg}$, respectively; greater than what was observed for those $\leq 45$ years (48). However, the median intake of VLCN n-3 PUFA ( $3.7 \mathrm{~g} /$ day) was far higher than that provided by fish in the current study, and would not be a usual intake of VLCN n-3 PUFA when supplements are not consumed. The effect of increased consumption of fish on blood pressure in older adults has not been specifically evaluated. Therefore, this outcome provided another novel component to our study. In our healthy group of older adults, we did not find an effect of increased fish intake on blood pressure. The beneficial effect of fish on blood pressure is thought to be through the increased synthesis of nitric oxide, a potent vasodilator, as well as the reduced production of the vasoconstrictor thromboxane A2, thus decreasing platelet aggregation and improving arterial compliance (49). As the meta-regression by Geleijnse et al. indicated that a greater effect on blood pressure was observed in hypertensives rather than normotensives (48), it is possible that we might have observed an effect on blood pressure if our study population also had elevated blood pressure. Nevertheless, further dose-response intervention studies assessing the relative effects of higher VLCN n-3 PUFA intakes on blood pressure in older adults are required, as well as the effect of increased fish intake in older adults with hypertension would be of value.

In our secondary analysis, among the small sample of adults with high baseline CRP concentrations, an 
increase in CRP was evident following the control diet, compared to those with low CRP on the control diet. This was a surprising result and it appears this type of diet could be unfavorable in this small group of healthy older adults, at least in the short-term. One study in adult women previously indicated that a higher intake of meat was associated with a higher level of CRP (50); whereas another study reported a diet high in red meat did not increase markers of oxidative stress and inflammation in men and women (51). These findings lend for further studies to assess the potential effects of CRP following a low fish, higher red meat diet, in healthy older adults with high CRP.

For Australian adults to lower their risk for CHD, it is recommended that $500 \mathrm{mg} /$ day of VLCN n-3 PUFA is consumed (two or three servings (150 g serve) of oily fish per week), and for patients with documented CHD is 1,000 $\mathrm{mg} /$ day (10). Therefore, the intention to supply the fish in this study at an amount nearly twice the current recommendations was to assist in compliance for a relatively short time-frame, as consumption of fish in this amount is not usual $(52,53)$. Our results demonstrated that shortterm consumption of a high fish diet is feasible. However, a higher fish intake in older adults who do not display cardiovascular and metabolic co-morbidities are unlikely to benefit from a diet higher in fish in an effort to further reduce CVD biomarkers, and thus, does not provide evidence that our results can be generalized into a public health recommendation for fish. We acknowledge that consumption of this amount of fish in the longer term is unlikely to be sustainable and other sources such as a fish oil supplement may be appropriate, if indeed, future studies identified a benefit from further reduction of already desirable cardiovascular biomarkers amongst older adults.

The study duration of 8-weeks was chosen as this timeframe is sufficient to alter the membrane composition and incorporation of omega- 3 fatty acids in cells and tissues (54); and changes in IL-6 and TNF- $\alpha$, which are mediators of CRP, can be noted within 6-weeks following VLCN n-3 PUFA in doses slightly higher (27) and much higher (55, 56) than that used in the current study. Provision of red meat in the control diet was based on the recommended 1-1.5 daily servings of 'meat, fish, poultry, eggs, nuts and legumes' from the Australian Guide to Healthy Eating for men and women $>60$ years (57) and that intake of red meat is generally lower than intake of poultry. We provided four servings of red meat per week, equivalent to $\sim 0.5$ serving/day red meat, or $68 \mathrm{~g} / \mathrm{day}$. This intake of meat was intermediate compared to consumption data in previous Australian studies $(52,53)$. In our study, we did not assess food intake prior to study commencement, therefore it is unclear whether the meat we provided is a usual intake for this group. We speculated that randomization would account for any baseline differences and the primary purpose of the dietary assessment was for compliance purposes. Another measure of dietary intake at baseline would have increased the burden for participants. We found good overall compliance with the study foods; however we did not specify which 3 days food was to be weighed nor on which days the study foods were to be consumed. This presents a further limitation to the study. Finally, we did not use high-sensitive ELISAs for IL-1, IL-6 and TNF- $\alpha$, resulting in few samples with detectable concentrations. High-sensitive ELISAs would have enabled us to identify detectable cytokine concentrations, and therefore would have assisted in determining whether a higher fish diet affects a composite of cytokine concentrations.

\section{Conclusions}

Eight weeks consumption of four servings of fish per week did not affect serum cytokine concentrations, lipids or blood pressure compared to a diet low in fish. In healthy older adults with low inflammatory burden, our results do not support that short-term consumption of mixed fish has a beneficial effect on selected cardiovascular biomarkers. Although a small sample size, the secondary analysis indicates that a diet more consistent with Australian dietary guidelines that is higher in meat and lower in fish, might increase CRP among older adults with CRP $\geq 3 \mathrm{mg} / \mathrm{L}$. Further, larger studies utilizing the same high fish intervention are required to substantiate this finding in healthy older adults with high CRP.

\section{Conflict of interest and funding}

This work was supported by the Australian Seafood Corporate Research Centre but had no input into the results presented in the current report. No conflict of interest exists for any author.

\section{References}

1. Roubenoff R, Roubenoff RA, Cannon JG, Kehayias JJ, Zhuang H, Dawson-Hughes B, Dinarello CA, et al. Rheumatoid cachexia: cytokine-driven hypermetabolism accompanying reduced body cell mass in chronic inflammation. J Clin Invest 1994; 93: 2379-86.

2. Holmes C, Cunningham C, Zotova E, Woolford J, Dean C, Kerr S, et al. Systemic inflammation and disease progression in Alzheimer disease. Neurology 2009; 73: 768-74.

3. Reale M, Iarlori C, Thomas A, Gambi D, Perfetti B, Di Nicola $\mathrm{M}$, et al. Peripheral cytokines profile in Parkinson's disease. Brain Behav Immun 2009; 23: 55-63.

4. Hamer M, Chida Y. Associations of very high C-reactive protein concentration with psychosocial and cardiovascular risk factors in an ageing population. Atherosclerosis 2009; 206: 599-603.

5. Koenig W, Khuseyinova N, Baumert J, Meisinger C. Prospective study of high-sensitivity C-reactive protein as a determinant of mortality: results from the MONICA/KORA Augsburg Cohort Study, 1984-1998. Clin Chem 2008; 54: 335-42.

6. Libby P, Ridker PM, Maseri A. Inflammation and atherosclerosis. Circulation 2002; 105: 1135-43. 
7. Lloyd-Jones DM, Evans JC, Levy D. Hypertension in adults across the age spectrum: current outcomes and control in the community. JAMA 2005; 294: 466-72.

8. World Health Federation. Hypertension: hypertension and cardiovascular disease. Geneva, Switzerland: World Health Federation; 2013.

9. Flood VM, Webb KL, Rochtchina E, Kelly B, Mitchell P. Fatty acid intakes and food sources in a population of older Australians. Asia Pac J Clin Nutr 2007; 16: 322-30.

10. Heart Foundation. Position statement: fish, fish oils, n-3 polyunsaturated fatty acids and cardiovascular health; 2008. http://www.heartfoundation.org.au/SiteCollectionDocuments/ Fish-position-statement.pdf [cited 22 June 2012].

11. Howe P, Meyer B, Record S, Baghurst K. Dietary intake of long-chain omega-3 polyunsaturated fatty acids: contribution of meat sources. Nutrition 2006; 22: 47-53.

12. Grieger JA, Miller M, Cobiac L. Fish consumption and use of omega 3 supplements in a sample of older Australians. Nutr Diet 2013; 70: 227-35.

13. Lopez-Garcia E, Schulze MB, Manson JE, Meigs JB, Albert $\mathrm{CM}$, Rifai N, et al. Consumption of (n-3) fatty acids is related to plasma biomarkers of inflammation and endothelial activation in women. J Nutr 2004; 134: 1806-11.

14. Pischon T, Hankinson SE, Hotamisligil GS, Rifai N, Willett WC, Rimm EB. Habitual dietary intake of n-3 and n-6 fatty acids in relation to inflammatory markers among US men and women. Circulation 2003; 108: 155-60.

15. van Bussel BC, Henry RM, Schalkwijk CG, Ferreira I, Feskens EJ, Streppel MT, et al. Fish consumption in healthy adults is associated with decreased circulating biomarkers of endothelial dysfunction and inflammation during a 6-year follow-up. J Nutr 2011; 141: 1719-25.

16. Niu K, Hozawa A, Kuriyama S, Ohmori-Matsuda K, Shimazu $\mathrm{T}$, Nakaya N, et al. Dietary long-chain $\mathrm{n}-3$ fatty acids of marine origin and serum C-reactive protein concentrations are associated in a population with a diet rich in marine products. Am J Clin Nutr 2006; 84: 223-9.

17. He K, Liu K, Daviglus ML, Jenny NS, Mayer-Davis E, Jiang R, et al. Associations of dietary long-chain $n-3$ polyunsaturated fatty acids and fish with biomarkers of inflammation and endothelial activation (from the Multi-Ethnic Study of Atherosclerosis [MESA]). Am J Cardiol 2009; 103: 1238-43.

18. Zampelas A, Panagiotakos DB, Pitsavos C, Das UN, Chrysohoou C, Skoumas Y, et al. Fish consumption among healthy adults is associated with decreased levels of inflammatory markers related to cardiovascular disease: the ATTICA study. J Am Coll Cardiol 2005; 46: 120-4.

19. Lopez-Garcia E, Schulze MB, Fung TT, Meigs JB, Rifai N, Manson JE, et al. Major dietary patterns are related to plasma concentrations of markers of inflammation and endothelial dysfunction. Am J Clin Nutr 2004; 80: 1029-35.

20. Nettleton JA, Steffen LM, Mayer-Davis EJ, Jenny NS, Jiang R, Herrington DM, et al. Dietary patterns are associated with biochemical markers of inflammation and endothelial activation in the Multi-Ethnic Study of Atherosclerosis (MESA). Am J Clin Nutr 2006; 83: 1369-79.

21. Gerhard GT, Patton BD, Lindquist SA, Wander RC. Comparison of three species of dietary fish: effects on serum concentrations of low-density-lipoprotein cholesterol and apolipoprotein in normotriglyceridemic subjects. Am J Clin Nutr 1991; 54: 334-9.

22. Mori TA, Vandongen R, Beilin LJ, Burke V, Morris J, Ritchie J. Effects of varying dietary fat, fish, and fish oils on blood lipids in a randomized controlled trial in men at risk of heart disease. Am J Clin Nutr 1994; 59: 1060-8.
23. Paulo MC, Andrade AM, Andrade ML, Morais MG, Kiely M, Parra D, et al. Influence of n-3 polyunsaturated fatty acids on soluble cellular adhesion molecules as biomarkers of cardiovascular risk in young healthy subjects. Nutr Metab Cardiovasc Dis 2008; 18: 664-70.

24. van Houwelingen $\mathrm{R}$, Zevenbergen $\mathrm{H}$, Groot $\mathrm{P}$, Kester A, Hornstra G. Dietary-fish effects on serum lipids and apolipoproteins, a controlled study. Am J Clin Nutr 1990; 51: 393-8.

25. Hallund J, Madsen BO, Bugel SH, Jacobsen C, Jakobsen J, Krarup H, et al. The effect of farmed trout on cardiovascular risk markers in healthy men. Br J Nutr 2010; 104: 1528-36.

26. Lindqvist HM, Langkilde AM, Undeland I, Sandberg AS. Herring (Clupea harengus) intake influences lipoproteins but not inflammatory and oxidation markers in overweight men. Br J Nutr 2009; 101: 383-90.

27. Meydani SN, Lichtenstein AH, Cornwall S, Meydani M, Goldin BR, Rasmussen $\mathrm{H}$, et al. Immunologic effects of national cholesterol education panel step-2 diets with and without fish-derived N-3 fatty acid enrichment. J Clin Invest 1993; 92: 105-13.

28. Moore CS, Bryant SP, Mishra GD, Krebs JD, Browning LM, Miller GJ, et al. Oily fish reduces plasma triacylglycerols: a primary prevention study in overweight men and women. Nutrition 2006; 22: 1012-24.

29. Pot GK, Geelen A, Majsak-Newman G, Harvey LJ, Nagengast FM, Witteman BJ, et al. Increased consumption of fatty and lean fish reduces serum C-reactive protein concentrations but not inflammation markers in feces and in colonic biopsies. $\mathrm{J}$ Nutr 2010; 140: 371-6.

30. Seierstad SL, Seljeflot I, Johansen O, Hansen R, Haugen M, Rosenlund G, et al. Dietary intake of differently fed salmon; the influence on markers of human atherosclerosis. Eur J Clin Invest 2005; 35: 52-9.

31. Tsitouras PD, Gucciardo F, Salbe AD, Heward C, Harman SM. High omega-3 fat intake improves insulin sensitivity and reduces CRP and IL6, but does not affect other endocrine axes in healthy older adults. Horm Metab Res 2008; 40: 199-205.

32. Pot GK, Habermann N, Majsak-Newman G, Harvey LJ, Geelen A, Przybylska-Philips K, et al. Increasing fish consumption does not affect genotoxicity markers in the colon in an intervention study. Carcinogenesis 2010; 31: 1087-91.

33. Williams P, Droulez V. Australian red meat consumptionimplications of changes over 20 years on nutrient composition. Food Australia 2010; 62: 87-94.

34. Panagiotakos DB, Zeimbekis A, Boutziouka V, Economou M, Kourlaba G, Toutouzas P, et al. Long-term fish intake is associated with better lipid profile, arterial blood pressure, and blood glucose levels in elderly people from Mediterranean islands (MEDIS epidemiological study). Med Sci Monit 2007; 13: CR307-12.

35. Virtanen JK, Nyantika AN, Kauhanen J, Voutilainen S, Tuomainen TP. Serum long-chain n-3 polyunsaturated fatty acids, methylmercury and blood pressure in an older population. Hypertens Res 2012; 35: 1000-4.

36. Ramel A, Martinez JA, Kiely M, Bandarra NM, Thorsdottir I. Moderate consumption of fatty fish reduces diastolic blood pressure in overweight and obese European young adults during energy restriction. Nutrition 2010; 26: 168-74.

37. Erkkila AT, Schwab US, de Mello VD, Lappalainen T, Mussalo $\mathrm{H}$, Lehto $\mathrm{S}$, et al. Effects of fatty and lean fish intake on blood pressure in subjects with coronary heart disease using multiple medications. Eur J Nutr 2008; 47: 319-28.

38. Department of Health and Ageing. Australian guide to healthy eating; 2013. http://www.eatforhealth.gov.au/sites/default/files/ files/public_consultation/n55d_draft_dietary_guidelines_agthe_ 111212.pdf [cited 20 February 2013]. 
39. Warnick GR, Knopp RH, Fitzpatrick V, Branson L. Estimating low-density lipoprotein cholesterol by the Friedewald equation is adequate for classifying patients on the basis of nationally recommended cutpoints. Clin Chem 1990; 36: 15-9.

40. Makrides M, Neumann MA, Gibson RA. Effect of maternal docosahexaenoic acid (DHA) supplementation on breast milk composition. Eur J Clin Nutr 1996; 50: 352-7.

41. Micallef MA, Garg ML. Anti-inflammatory and cardioprotective effects of n-3 polyunsaturated fatty acids and plant sterols in hyperlipidemic individuals. Atherosclerosis 2009; 204: 476-82.

42. Lee TH, Hoover RL, Williams JD, Sperling RI, Ravalese J, 3rd, Spur BW, et al. Effect of dietary enrichment with eicosapentaenoic and docosahexaenoic acids on in vitro neutrophil and monocyte leukotriene generation and neutrophil function. $\mathrm{N}$ Engl J Med 1985; 312: 1217-24.

43. Calder PC. Polyunsaturated fatty acids, inflammation, and immunity. Lipids 2001; 36: 1007-24.

44. Calder PC. Fatty acids and inflammation: the cutting edge between food and pharma. Eur J Pharmacol 2011; 668(Suppl 1): S50-8.

45. Sijben JW, Calder PC. Differential immunomodulation with long-chain n-3 PUFA in health and chronic disease. Proc Nutr Soc 2007; 66: 237-59.

46. Kaptoge S, Di Angelantonio E, Lowe G, Pepys MB, Thompson $\mathrm{SG}$, Collins R, et al. C-reactive protein concentration and risk of coronary heart disease, stroke, and mortality: an individual participant meta-analysis. Lancet 2010; 375: 132-40.

47. Ridker PM. Clinical application of C-reactive protein for cardiovascular disease detection and prevention. Circulation 2003; 107: 363-9.

48. Geleijnse JM, Giltay EJ, Grobbee DE, Donders AR, Kok FJ. Blood pressure response to fish oil supplementation: metaregression analysis of randomized trials. J Hypertens 2002; 20: 1493-9.

49. Mori TA, Woodman RJ. The independent effects of eicosapentaenoic acid and docosahexaenoic acid on cardiovascular risk factors in humans. Curr Opin Clin Nutr Metab Care 2006; 9: 95-104.
50. Azadbakht L, Esmaillzadeh A. Red meat intake is associated with metabolic syndrome and the plasma C-reactive protein concentration in women. J Nutr 2009; 139: 335-9.

51. Hodgson JM, Ward NC, Burke V, Beilin LJ, Puddey IB. Increased lean red meat intake does not elevate markers of oxidative stress and inflammation in humans. J Nutr 2007; 137: 363-7.

52. Flood VM, Burlutsky G, Webb KL, Wang JJ, Smith WT, Mitchell P. Food and nutrient consumption trends in older Australians: a 10-year cohort study. Eur J Clin Nutr 2010; 64: 603-13.

53. McLennan W, Podger A. National Nutrition Survey: foods eaten, 1995. Australia. Australian Bureau of Statistics Catalogue No. 4804.0. Canberra; 1999. http://www.abs.gov.au/AUSSTATS/ abs@.nsf/0/9A125034802F94CECA2568A9001393CE?Open Document [cited 7 July 2011].

54. Garg ML, Leitch J, Blake RJ, Garg R. Long-chain n-3 polyunsaturated fatty acid incorporation into human atrium following fish oil supplementation. Lipids 2006; 41: 1127-32.

55. Endres S, Ghorbani R, Kelley VE, Georgilis K, Lonnemann G, van der Meer JW, et al. The effect of dietary supplementation with n-3 polyunsaturated fatty acids on the synthesis of interleukin-1 and tumor necrosis factor by mononuclear cells. N Engl J Med 1989; 320: 265-71.

56. Gibney MJ, Hunter B. The effects of short- and long-term supplementation with fish oil on the incorporation of n-3 polyunsaturated fatty acids into cells of the immune system in healthy volunteers. Eur J Clin Nutr 1993; 47: 255-9.

57. Department of Health and Ageing. Australian guide to healthy eating; 2007. http://www.health.gov.au/internet/main/publishing. nsf/content/E384CFA588B74377CA256F190004059B/\$File/fdcons.pdf [cited 20 February 2012].

*Jessica A. Grieger

Flinders University: Level 7E, Flinders Medical Centre

Flinders Drive, Bedford Park, SA 5042, Australia

Fax: +6I 82046406

Email: jessag00।@gmail.com 